\title{
A novel Myb homolog initiates Dictyostelium development by induction of adenylyl cyclase expression
}

\author{
Hideshi Otsuka and Peter J.M. Van Haastert ${ }^{\mathbf{1}}$ \\ Department of Biochemistry, University of Groningen, 9747 AG Groningen, The N etherlands
}

\begin{abstract}
Dictyostelium development is induced by starvation. The adenylyl cyclase gene ACA is one of the first genes expressed upon starvation. ACA produces extracellular CAMP that induces chemotaxis, aggregation, and differentiation in neighboring cells. Using insertional mutagenesis we have isolated a mutant that does not aggregate upon starvation but is rescued by adding extracellular cAMP. Sequencing of the mutated locus revealed a new gene, D dMY B2, whose product contains three Myb repeats, the DNA-binding motif of Myb-related transcription factors. D dmyb2-null cells show undetectable levels of A CA transcript and no CAMP production. Ectopic expression of ACA from a constitutive promotor rescues differentiation and morphogenesis of D dmyb2-null mutants. The results suggest that development in D ictyostelium starts by starvation-mediated DolMyb2 activation, which induces adenylyl cyclase activity producing the differentiation-inducing signal CAMP.
\end{abstract}

[Key Words: myb-related gene; starvation response; REMI; adenylyl cyclase; CAM P oscillation; transcriptional regulation]

Received N ovember 11, 1997; revised version accepted March 5, 1998

Transcription factors and secreted signaling molecules play pivotal roles during development in multicellular organisms. The identification of mutants defective in those factors may provide powerful insight into the mechanisms of developmental regulation. Dictyostelium is an ideal model organism to investigate developmental regulation, because mutants that arrest at a certain stage of development are easy to isolate, and the secreted factor missing in such mutants can be provided by wild-type cells in simple mixing experiments (Loomis 1996; Parent and Devreotes 1996). Dictyostelium cells grow vegetatively as individual amebae feeding on bacteria or defined axenic media. Upon starvation they gather with neighboring cel Is forming aggregates consisting of up to $10^{5}$ cells. A ggregating cells relay extracelluIar CAMP signals and move to the signaling center by chemotaxis to CAMP. After aggregation, cells behave as in more complex multicellular organisms; they differentiate to specific cell types, perform coordinated morphogenetic movement, and finally culminate into a fruiting body consisting of spores on top of a supporting stalk.

Development in Dictyostelium starts with the transcriptional activation triggered by amino acid depletion, inducing the essential molecules to produce and sense extracellular CAMP, such as an adenylyl cyclase, cellsurface CAMP receptors (cARs) and specific $G$ protein

${ }^{1}$ Corresponding author.

E-MAIL haastert@chem.rugnl; FAX 31-50-3634165. $\alpha$-subunits (Klein et al. 1988; Kumagai et al. 1988, 1989; Pitt et al. 1992). Intercellular signal ing by secreted CAM P then induces the expression of another set of genes for the further stages of development (Kimmel and Firtel 1991). A denylyl cyclase ACA is the key enzyme of this CAMP signaling and its mRNA shows an immediate sharp increase by starvation. Therefore the components that mediate the induction of adenylyl cyclase should have the central role in the growth/development transition in Dictyostelium. Several mutants that lack adenylyl cyclase activity or its activation have been identified. They are called Synag mutants, because they do not aggregate in their clonal populations, missing the CAM P signaling, but do aggregate and proceed to further development in mixed populations with wild-type cells (Theibert and Devreotes 1986).

Using plasmid insertional mutagenesis we have isolated a new Synag mutant with unique bi ochemical features. It shows poor chemotaxis to CAM P and no CAM P relay, but makes normal fruiting bodies after a few hours of stimulation with experimentally applied CAMP pulses, suggesting a defect in the initiation of CAM P signaling. By sequencing the insertion site we identified a novel myb-related gene, DdMYB2, as a key component that induces Dictyostelium devel opment.

The vertebrate c-myb gene is essential for proliferation and differentiation of hematopoietic cells, and its truncated counterpart v-myb is responsible for the oncogenic transformation of myelomonocytic hematopoietic cells 
(Shen-Ong 1990). Both c-myb and v-myb encode transcriptional activators, but little is known about their target genes in the context of developmental control or the oncogenic transformation (N ess 1996). Proteins related to c-M yb have been identified and characterized as key regulators of differentiation and development in many eukaryotes, including vertebrates, fungi, insects, and plants (Lipsick 1996; Martin and Paz-Ares 1997). In Dictyostelium a Myb homolog, DdMybl, also called as $\mathrm{MybH}$, was identified previously (Stober-Grässer et al. 1992). The DN A-binding domain of D dM ybl shows $65 \%$ ami no acid identity to vertebrate c-M yb and is capable of binding to the same DN A sequence as c-M yb. However, target genes and function of DdM yb1 are not known.

In this report we demonstrate that the novel myb-related gene DdMYB2 is required for starvation-induced expression of the adenylyl cyclase ACA. Ectopic constitutive expression of ACA restores development of Ddmyb2-null cells, suggesting that DdMyb2 mediates the starvation signal and induces Dictyostelium development by direct or indirect activation of ACA gene expression.

\section{Results}

Isolation of Ddmyb2 mutants

To identify genes that regulate CAMP signaling in Dictyostelium devel opment, we isolated a set of aggregateless mutants using restriction enzyme-medi ated integration (REMI; Kuspa and Loomis 1992). REMI is a method of insertional mutagenesis, in which a linearized plasmid carrying a selection marker is integrated into the host genome with the help of a restriction enzyme. We screened 31 aggregateless mutants for CAM P-mediated activation of adenylyl and guanylyl cyclase, for chemotaxis to CAM P and folic acid, and for synergy with wildtype cells. Seven mutants were identified as Synags, as mixing them with wild-type cells restored development in these aggregatel ess mutants. M ost Synags have a si miIar phenotype as aca-null cells, not producing extracelIular CAMP but showing good chemotaxis to CAMP (Pitt et al. 1992). One Synag mutant, W67, showed a strongly reduced CAMP response and very weak chemotaxis to CAM P, suggesting a defect of a novel component that is required for both the secretion of CAMP and normal chemotaxis to CAMP.

A Southern blot of W67 genomic DNA probed with a part of the inserted plasmid revealed Bglll restriction sites flanking the insertion site (see Fig. 1A). Plasmid pRW67 was recovered from W67 genomic DN A digested with Bglll and was used to sequence the insertion-flanking region and to recapitulate the insertion event. For the latter, the plasmid was relinearized with Bglll and introduced into wild-type cells by electroporation. About $70 \%$ of transformants showed an agg ${ }^{-}$phenotype. Southern analysis of four agg ${ }^{-}$and six $\mathrm{agg}^{+}$clones revealed that all $\mathrm{agg}^{-}$clones had the expected homol ogous recombination, whereas all $\mathrm{agg}^{+}$clones contained the wild-type DN A fragment (data not shown). Therefore, we conclude
A.

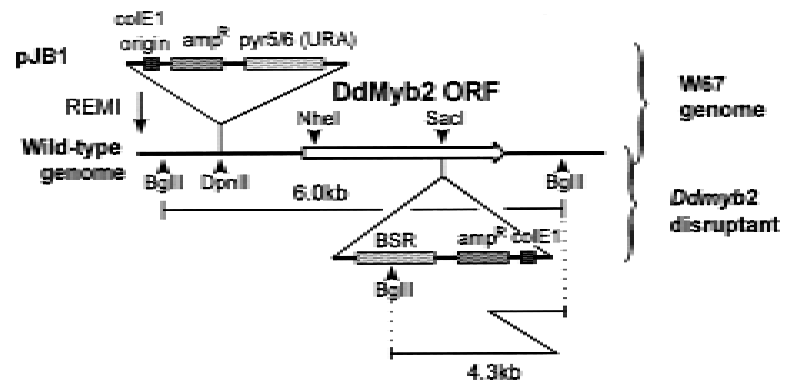

B

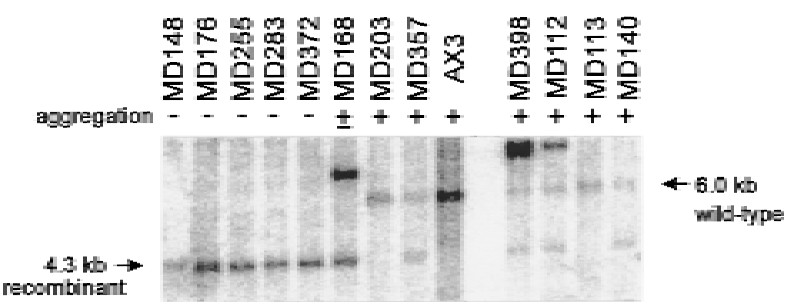

$\mathrm{C}$

wild-type Dolmyb2-

(Ax3) (MD255)

Time (hrs) $022 \quad 4 \quad 602246$

Dodvraz, 2.6mb -

Figure 1. The DdMYB2 locus and isolation of a Ddmyb2-null mutant. (A) REMI and gene targeting at DdMYB2 locus. W67 mutant was made by REMI of the BamH1-linearized plasmid pJB1 into the genome of uracil-auxothroph wild-type DH 1 with the restriction enzyme DpnlI. The DdMYB2 locus was isolated from genomic DNA using the restriction enzyme BgllI. The Ddmyb2-null mutant was made by homologous recombination in wild-type $A \times 3$ genome with pM KO1, which contains a BSR, and pBluescript at the Sacl site of the N hel-BgllI genomic DN A fragment. The expected sizes of BgllI fragments from wild-type cells and Ddmyb2 disruptant are indicated. (B) Southern analysis of the transformants with pMKO1. DNA was isolated from randomly picked transformants, digested with BglII, and probed with the Sacl-BgllI genomic fragment containing 3' portion of DdM YB2 gene. M D255 was used as Ddmyb2 disruptant for further analysis. (C) Expression of DdMYB2 in wild-type AX3 and in Ddmyb2-null mutant MD255. RNA was prepared from either growing cells or cells that had been starved in suspension for the time indicated. The bl ot was probed with partial CDNA for DdMYB2 RN A (nucleotides 1675-1974 in Fig. 2B).

that the observed W67 phenotype results from the plasmid integration and not from potential secondary mutations.

pRW67 was analyzed by sequencing, reveal ing that the plasmid was not integrated into the coding region of a gene but upstream of an open reading frame (ORF). We did not find a possible coding sequence at the other side of the insertion, or in the other strand of the recovered 
genomic DNA. The deduced amino acid sequence of the ORF shows strong homology with c-myb; the new gene is addressed as DdMYB2, and its sequence has been deposited in the EMBL N ucleotide Sequence Database (accession no. AJ002383). The expression of DdMYB2 RN A was examined in wild-type and W67 cells. A N orthern bl ot probed with the recovered fragment of genomic DN A reveal ed two messengers in wild-type cells, one of which was absent in mutant W67 (data not shown; result essentially the same as the Northern blot of MD255 shown in Fig. 2).

To prove that the W67 phenotype is caused by the

A

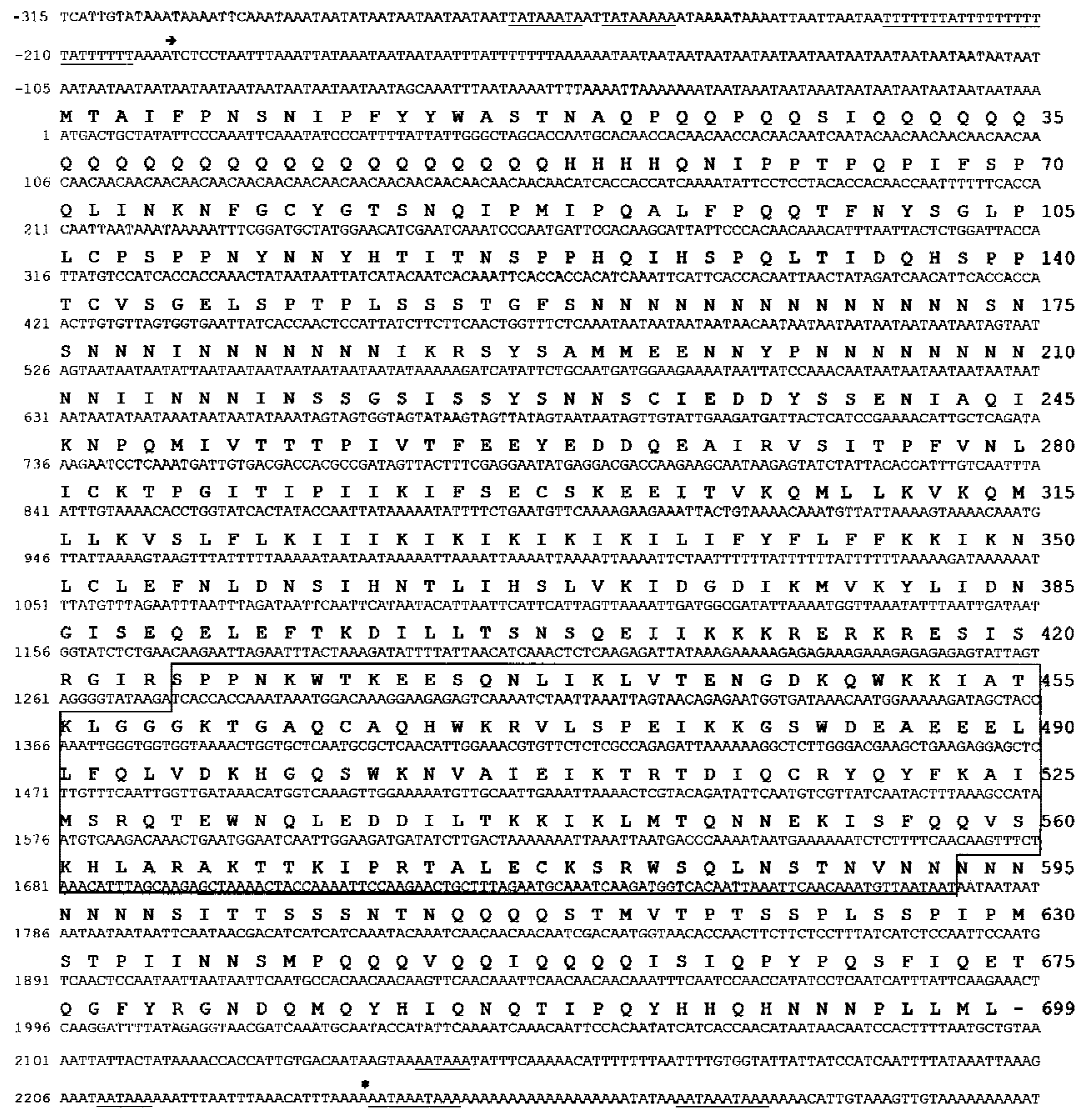

Figure 2. A novel myb-related gene DdMYB2. (A) Nucleotide and deduced amino acid sequence of the DdMYB2 gene. Putative TATA-oligo(dT) and polyadenylation signals are underlined. (arrow) The putative start site of transcription, $\left(^{*}\right)$ the end of a cDN A isolate. The deduced amino acids sequence from 425 to 592 (boxed) consists of three Myb repeats. (B) Alignment of $M y b$ domains from various Myb-related proteins. (D.d.) Dictyostelium discoideum Myb2 (this study), Myb1 (or MybH; Stober-Gräser et al. 1992); (H.s.) Homo sapiens c-Myb (Majello et al. 1986); (S.p.) Shizosacharomyces pombe Cdc5 (Ohi et al. 1994), (D.m.) Drosophila melanoguster C-M yb (Katzen et al. 1985); (Z.m.) Zea mays P (Grotewold et al. 1991). Boxes indicate amino acid identity between $\mathrm{DdM}$ yb2 and other proteins. Secondary structure prediction using PHD is shown for DdM yb2: ( $\rightarrow$ loop, ( $\square$ ) helix, (.) no prediction. The c-Myb helices determined by nuclear magnetic resonance (N MR) are indicated with shaded boxes (Ogata et al. 1994).
B

\section{Repeat 1}

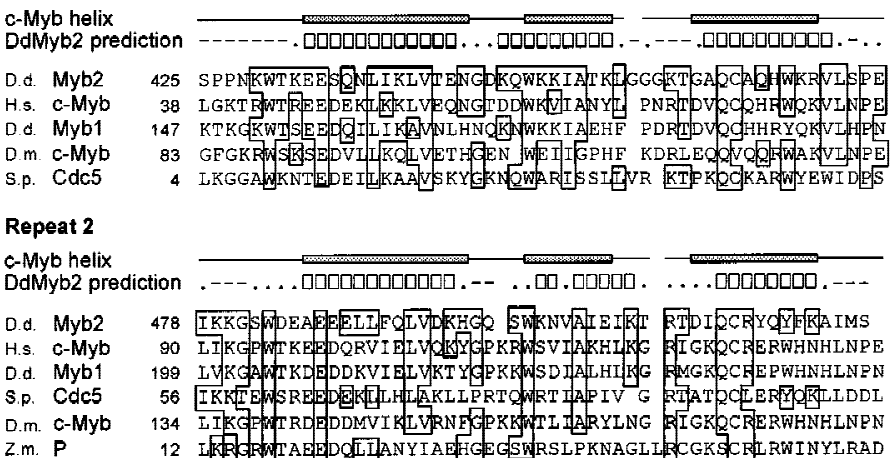

Z.m. P

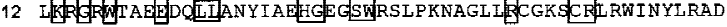

Repeat 3

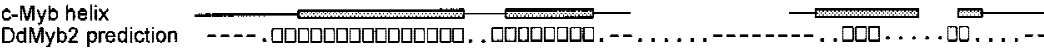

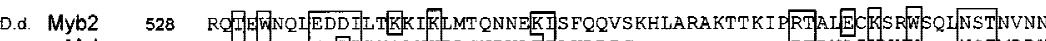

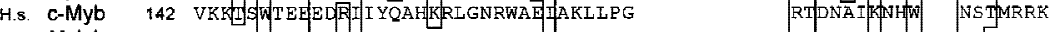

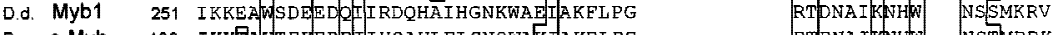

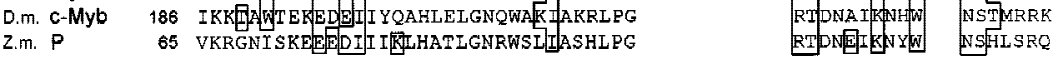


reduced expression of DdMYB2, we performed gene targeting toward the coding region (Fig. 1A). The targeting construct pMKO1 contains the DdMYB2 coding region with an insertion of an Escherichia coli vector and a blasti cidin cassette (Sutoh 1993). pM KO1 was linearized and introduced into wild-type cells. Among 296 clones randomly taken from a pool of transformants resistant to blasticidin, 270 clones were agg-, 13 clones were mutants making very small aggregates but no fruiting bodies $\left(\mathrm{agg}^{+} / 7\right.$, and 13 clones showed normal aggregation $\left(\mathrm{agg}^{+}\right)$. A mong these, $6 \mathrm{agg}^{-}, 1 \mathrm{agg}^{+} /^{-}$, and $6 \mathrm{agg}^{+}$clones were analyzed by Southern blotting (Fig. 1B). The blot was probed with the Sacl-Bglll fragment of genomic DN A containing the 3' end of DdMYB2. By gene replacement, the $6.0-\mathrm{kb}$ Bglll band of wild-type is expected to shift to $4.3 \mathrm{~kb}$. All $\mathrm{agg}^{-}$clones have only the $4.3-\mathrm{kb}$ band and all $\mathrm{agg}^{+}$clones still possess the $6.0-\mathrm{kb}$ band. Some $\mathrm{agg}^{+}$clones (e.g., MD203) have only the 6.0-kb band, as expected. Other $\mathrm{agg}^{+}$clones (e.g., MD357) possess both 4.3- and 6.0-kb bands. We suppose that these $\mathrm{agg}^{+}$clones were transformed to bl asticidin-resistant clones with undigested plasmid by homologous recombination with a single crossover; then the fused gene consisting of the $5^{\prime}$ part of endogenous gene and the $3^{\prime}$ part of the targeting construct remains intact. We chose the Ddmyb2 disruptant clone MD255 for further analysis (Fig. 3 A and B shows aggregatel ess phenotype of MD255 and wild-type fruiting bodies). Ectopic expression of DdMYB2 in MD255 suppressed the phenotypic defects (data not shown). This confirms that the phenotypic defects in W67 and the Ddmyb2 disruptants result from the failed expression of DdMYB2.

\section{Expression of DdMYB2}

U sing the Sacl-Bgl II fragment of genomic DN A, a partial CDNA clone was isolated from a CDNA library made from 5-hr starved cells. The cDN A was used as a probe for $\mathrm{N}$ orthern anal ysis to examine DdMYB2 expression in wild-type and Ddmyb2-null cells. Two transcripts with slightly different sizes $\sim 2.6-\mathrm{kb}$ were detected in wildtype cells (Fig. 1C), whereas only the smaller transcript was visible in Ddmyb2-null cells. This identifies the larger one as the DdMYB2 transcript and suggests the existence of a gene cl osely related to DdMYB2. This second gene is not likely DdMYB1, which has low homology in nucleotide sequence with DdMYB2. A N orthern blot of RNA from W67 cells also reveals the absence of the larger transcript (data not shown).

The Northern blot in Figure $1 C$ shows that the DdMYB2 transcript is present during axenic growth. DdMYB2 expression increases about five-fold during the first $2 \mathrm{hr}$ of starvation and decreases rapidly to $10 \%$ of the maximal level during the subsequent $4 \mathrm{hr}$ of starvation.

\section{A novel myb-related gene: DdMYB2}

The isolated genomic fragment in pRW67 contains a single ORF of 699 codons (Fig. 2A). The sequence prior to
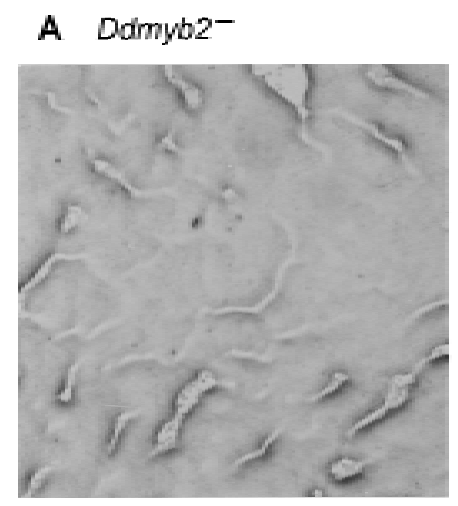

\section{B Wild-type}

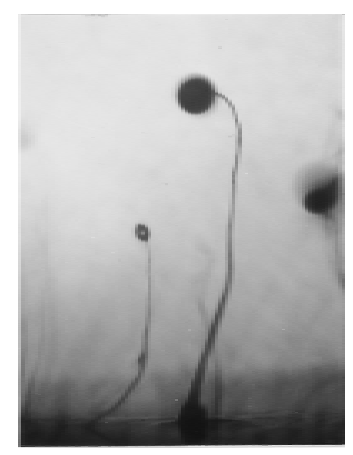

C Damyb2- +cAMP pulses
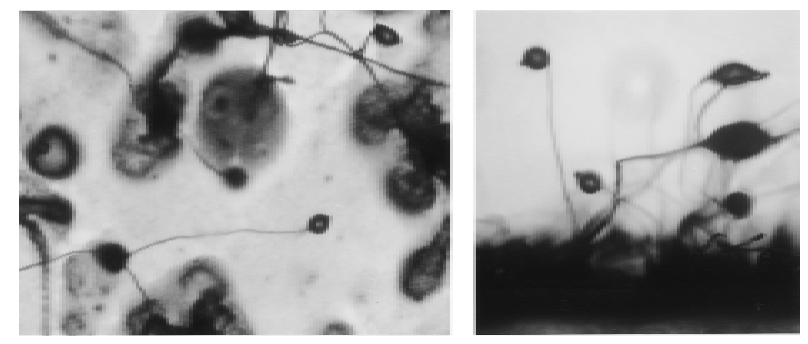

D Ddmyb2-/ACA
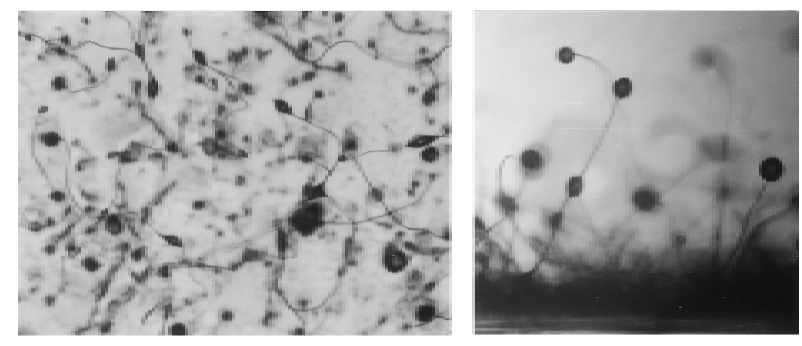

Figure 3. Phenotype of the Ddmyb2-null mutant and rescue by exogenous CAM P pulses or by ectopic expression of ACA. Cells starved in phosphate buffer for $5 \mathrm{hr}$ were plated on nonnutrient agar at a density of $2 \times 10^{6} / \mathrm{cm}^{2}$. The photographs were taken after $30 \mathrm{hr}$; overhead views at left; side views at right. (A) No aggregation of Ddmyb2-null cells; (B) Wild-type fruiting bodies; development and fruiting body formation are restored by addition of exogenous CAMP pulses to Ddmyb2-null cells during 5 hr of starvation (C) or by constitutive expression of ACA (D). Scale bar is $1 \mathrm{~mm}$.

the ORF is highly $A T$ rich and contains a pair of TATAAA(T/A)A followed by oligo(dT), a usual Dictyostelium transcription start sequence (Kimmel and Firtel 1983). The ORF starts with the sequence AAAATG, which is a common translation initiation signal in Dictyostelium. The 3' end of the transcript was determined by isolation of CDNA and contains several AATAAA sequences known as polyadenylation signal. Although the ORF is continuous (no frameshifts or stop codons), it contains a stretch of 87 nucleotides (nucleotide 955-1041 in Fig. 2A) that has the characteristics of a typical Dic- 
tyostelium intron consisting of oligo(dT) and oligo(dA) stretches flanked by consensus $5^{\prime}$ and $3^{\prime}$ splice sites GTAAGT and AG, respectively. Furthermore, no frameshift will occur when this region is spliced out. To examinethe presence of an intron we performed PCR using primers flanking this region with genomic DNA and cDNA from a $\lambda$ gt11 cDNA library prepared from 5-hr starved cells as template. We observed products that were indistinguishable in size, suggesting that region 955-1041 was not spliced out in the mRN A used to prepare the cDN A library (data not shown).

The deduced amino acid sequence predicts a protein of 80.4 kD. A mino acids 425-561 show strong homology to a motif found in the Myb family of transcription factors. Myb-related proteins contain two or three imperfect repeats of $\sim 50$ amino acids (Frampton et al. 1989). Each $M y b$ repeat has a similar folding architecture, consisting of three well-defined helices. The second and the third helix form the helix-turn-helix structure. In vertebrate c-Myb, which contains three Myb repeats (R1, R2, R3), the third helices of $R 2$ and $R 3$ are invol ved in the specific base recognition for DNA binding (Ogata et al. 1994; N ess 1996).

The related domain of Dictyostelium Myb2 is located in the carboxy-terminal portion of the protein and contains three $\mathrm{M}$ yb repeats (Fig. $2 \mathrm{~B}$ ). The homology with the corresponding repeats in $\mathrm{c}-\mathrm{M}$ yb is strongest for $\mathrm{R} 1$ (43\% identity), whereas each of R2 and R3 shows 30\% and $27 \%$ identity with the corresponding repeat in c-Myb, respectively. $R 3$ in DdM yb2 shows a 12-amino-acid insertion between the second and the third helix. Secondary structure prediction using multisequence al ignment (PHD: Profile fed neural network systems from HeiDelberg; Rost et al. 1994) predicts helix structures for DdM yb2 at the amino acids corresponding to helices of $c-M y b$, suggesting that the $M y b$ repeats of $D d M y b 2$ have a structure similar to that of c-Myb. A potential nuclear Iocalization signal, 408-IKKKRERKR, is located just before the Myb domain (Garcia-Bustos et al. 1991). Beside the Myb domain we could not find any region with significant homology to other proteins in the database.

\section{Exogenous CAMP pulses rescue morphogenesis} and differentiation of Ddmyb2-null cells

Most Synag mutants show defects in CAMP signaling that can be at least partially restored by addition of CAMP pulses. Because the original mutant, W67, was identified as a Synag mutant, we examined the possibility that exogenous CAMP pulses can restore the development of MD255 Ddmyb2-null cells. They were stimulated with $100 \mathrm{nM} \mathrm{CAMP}$ at 5-min intervals for different lengths of time in suspension and plated on non-nutrient agar plates. Unpulsed cells or cells pulsed for up to $4.5 \mathrm{hr}$ formed no fruiting bodies. However, after pulsing for $6 \mathrm{hr}$ with CAM P, $80 \%$ of cells on the plates were recruited into aggregates, which developed to fruiting bodies (Fig. 3C). Spores in the fruiting bodies were morphologically indistinguishable from wild-type spores and resistant to treatment with detergent. They germinated upon food addition, and all colonies were aggregateless (data not shown). These findings led us to examine the CAMP signal transduction pathways in Ddmyb2-null cells starved with exogenous CAMP pulses comparing with those without pulses.

\section{Signal transduction in Ddmyb2-null cells}

CAMP binding Secreted CAMP is detected by CARs. During early devel opment, CAR 1 represents most of cellsurface cAM P-binding activity and mediates many of the CAM P-induced responses, such as induction of gene expression, CAMP secretion, and chemotaxis (Sun and Devreotes 1991; Parent and Devereotes 1996). Expression of CAR 1 is regulated transcriptionally and posttranscriptionally during Dictyostelium devel opment. CAR1 mRNA is induced by starvation and by stimulation with extracellular CAMP (Louis et al. 1993). The binding of CAM P to wild-type cells increases to a maximal level at the 5.5-hr time point (Fig. 4A). In contrast, after an initial increase, Ddmyb2-null cells do not express a further increase of CAM P-binding activity upon starvation; at 5.5 hrs CAM P-binding activity is only $15 \%$ that of wild-type cells.

Exogenously added CAMP pulses strongly induce cAMP-binding to Ddmyb2-null cells to about half the maximal level of wild-type cells (Fig. 4A). The induction of CAMP-binding sites on Ddmyb2-null cells by CAMP pulses was maximal between 5.5 and $7 \mathrm{hr}$ of time point (after 4.5 and $6 \mathrm{hr}$ of CAMP pulsation, respectively). A similar time course was observed in the rescue of fruiting body formation by CAM P pul sing, suggesting that the phenotypic defects of Ddmyb2-null cells can be suppressed by CAM P-induced gene expression mediated by the cell-surface receptor.

Chemotaxis The chemotactic response of Ddmyb2null cells to CAM P and folic acid was examined using the small population assay. The Ddmyb2-null cells starved for $5 \mathrm{hr}$ showed weak chemotaxis to $10^{-6} \mathrm{M}$ CAM P but do not respond to $10^{-8}$ or $10^{-7} \mathrm{M}$ CAM P, whereas wild-type cells show clear responses to all these concentrations of CAMP. U pon pulsing Ddmyb2-null cells with $10^{-7} \mathrm{M}$ CAMP for $5 \mathrm{hr}$, the mutant cells show normal chemotaxis to CAM P (data not shown). Chemotaxis to folic acid during the vegetative stage is identical in wild-type and mutant cells (data not shown). These observations confirm that the defect of Ddmyb2-null cells is specific to CAMP signaling that can be restored by CAMP pulses.

CAMP-mediated CGMP response The CAMP binding to CAR1 induces production of intracellular signaling molecules, such as $I P_{3}, C A M P$, and CGM P. In wild-type cells an extracellular CAM P stimulus induces CGM P accumulation with a peak at $10 \mathrm{sec}$; after the production by guanylyl cyclase, cGMP is degraded by intracellular phosphodiesterase. Synthesis of cGMP appears to be tightly linked to CAMP and folic acid chemotaxis (Parent and Devreotes 1996). Ddmyb2-null cells show significant accumulation of CGM P upon the CAM P stimulation 

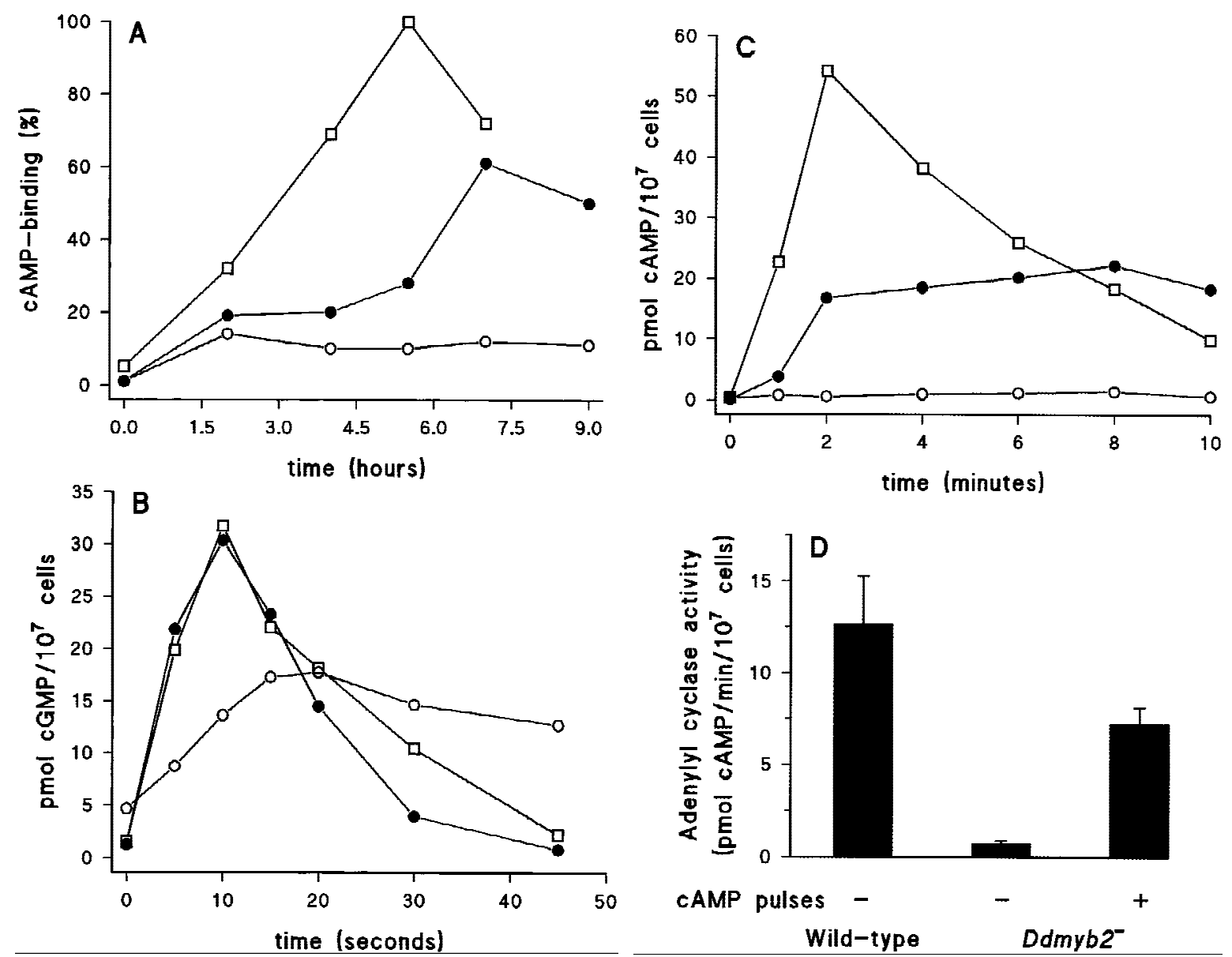

Figure 4. Defective signal transduction in Ddmyb2-null cells and its rescue by cAMP pulses. Cells were starved in suspension and pulsed with or without $100 \mathrm{nM}$ CAMP added every $5 \mathrm{~min}$. Wild-type $A \times 3$ without pulses $(\square)$; Ddmyb2-null cells without $(O)$ or with pulses (-). (A) Cells were starved with or without CAMP pulses for the indicated time and assayed for CAM P-binding activity. (B) CAM P-induced CGMP response, (C) CAMP relay response, and (D) adenylyl cyclase activity in wild-type AX3 cells starved for 5 hr or Ddmyb2-null cells starved for $7 \mathrm{hr}$. Adenylyl cyclase activity was measured in cell lysates with $\mathrm{M} \mathrm{n}^{2+}-\mathrm{ATP}$ as substrate.

(Fig. 4B); the response is $\sim 50 \%$ of that in wild-type cells. However if cells are pulsed for $6 \mathrm{hr}$ with exogenous CAMP, the CGMP response is restored completely (Fig. 4B). Because unpulsed Ddmyb2-null cells have low levels of CAMP binding, this may explain the reduction of cGMP response. In the mutant, the basal cGMP level is about twofold higher than that of wild-type cells, and the rate of CGMP degradation is slower, which might result from low level of phosphodiesterase activity; these aberrations are al so restored by treating the cells with CAMP pulses.

The folic acid-mediated cGMP response in Ddmyb2null cells is normal (data not shown), which is consistent with the normal chemotaxis of these cells to folic acid.

CAMP relay response and adenylyl cyclaseactivity Development and signal transduction in Ddmyb2-null cells are restored by CAMP pulses (Figure 3 and 4A,B). This suggests that mutant cells lack autonomous oscillations of CAMP, which are generated through synchronized CAMP production stimulated by extracellular CAM P (cAM P relay). This CAM P relay response is absent in Ddmyb2-null cells (Fig. 4C). Treatment of mutant cells with CAMP pulses for several hours partly restores the relay response to approximately half the level of the response in wild-type cells (Fig. 4C).

This severe defect in CAM $P$ relay response in the mutant, combined with the moderate reduction of CAM Pbinding and CGMP response, suggests another defect in CAMP production in addition to the reduced receptor expression (Fig. 4A-C). A denylyl cyclase activity in cell lysates was measured in the presence of $\mathrm{Mn}^{2+}$, which bypasses the requirement for activation by $G$ protein or receptor (Theibert and Devreotes 1986). The lysate from the mutant cells has very low activity of adenylyl cyclase, $5 \%$ of wild type; it increases to $56 \%$ of wild type by pulsing the cells with CAMP for $6 \mathrm{hr}$ (Fig. 4D). This demonstrates that the reduced relay response in Ddmyb2-null cells is largely because of the very low activity of adenylyl cyclase.

Expression of genes encoding CAMP-signaling components Because DdM yb2 has a M yb motif, the defects in Ddmyb2-null cells may relate to transcriptional regula- 


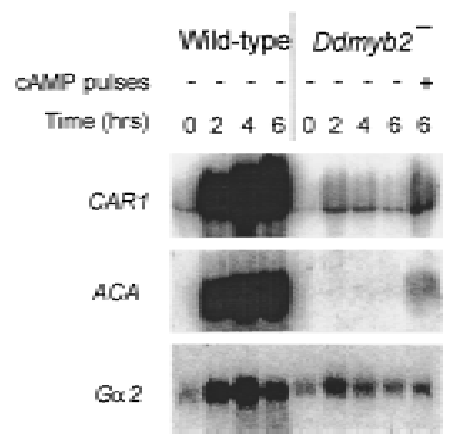

Figure 5. Gene expression of CAMP-signaling components in Ddmyb2-null cells. Wild-type AX3 and Ddmyb2-null cells were starved in suspension with or without CAM P pulses for the indicated time. Total mRNA was isolated and analyzed. The Northern blot shows the expression of CAR1, ACA, and G $\alpha 2$.

tion. We compared the expression of the CAMP receptor gene CAR1 (Klein et al. 1988), the adenylyl cyclase gene ACA (Pitt et al. 1992), and the $G$ protein $\alpha$ subunit gene $\mathrm{G} \alpha 2$ (Kumagai et al. 1988) in Ddmyb2-null and wildtype cells by $\mathrm{N}$ orthern analysis (Fig. 5). CAR1 mRNA levels are strongly reduced in Ddmyb2-null cells. Although exogenous CAM P pulsing induces the expression of CAR1, they are still significantly lower than in wildtype cells, which is in accordance with biochemical data. It is notable that in the mutant, the expression of ACA is undetectable without CAMP pulses, but induced by CAMP pulses. The expression of $\mathrm{G} \alpha 2$ is slightly reduced in Ddmyb2-null cells. Though induction by CAMP pulses was not detected on this blot, upon longer electrophoresis two different transcripts ( 2.3 and $2.7 \mathrm{~kb}$ ) were separated, revealing the several fold induction of the 2.3$\mathrm{kb}$ and reduction of the $2.7-\mathrm{kb}$ transcript (data not shown).

The messengers for CAR 1 and $\mathrm{G} \alpha 2$ are present at low levels in vegetative cells and have increased significantly during the first $2 \mathrm{hr}$ of starvation. Whereas in wild-type cells the expression of these genes increases further between 2 and $6 \mathrm{hr}$, it slightly decreases in Ddmyb2-null cells. The presence of low but significant levels of CAR 1 and $\mathrm{G} \alpha 2$ messenger in Ddmyb2-null cells explains the ability of these cells to show the CAM P-mediated CGM P responses and pulse-induced gene expression. The virtual absence of ACA messenger is consistent with the very low level of adenylyl cyclase activity and the lack of CAMP relay. It predicts that cells can not generate autonomous CAMP oscillations and therefore no autonomous pulse-induced gene expression. The low levels of CAR1 and $\mathrm{G} \alpha 2$ messenger in 6-hr starved Ddmyb2-null cells could be caused by the lack of this pulse-induced gene expression.

Ectopic expression of ACA but not CAR1 rescues morphogenesis in Ddmyb2-null cells

To confirm that the aggregateless phenotype of Ddmyb2null cells results from the reduced expression of ACA and/or CAR1, we transformed Ddmyb2-null cells with plasmids carrying ACA or CAR1 under the transcriptional control of the constitutive actin-15 promoter (Knecht et al. 1986; Johnson et al. 1991). Increased expression of ACA or CAR1 was confirmed by adenylyl cyclase or CAMP-binding assays using growing cells. While the Ddmyb2-/CAR1 strain remained aggregateless at low or high cell density (data not shown), the Ddmyb2 $/ A C A$ strain made fruiting bodies of nearly normal size and shape at high cell density (Fig. 3D); at low cell density, fruiting bodies were small and a part of the cells did not participate in cell aggregation.

Starved wild-type cells show autonomous CAM P oscillations with a periodicity of $\sim 4-6 \mathrm{~min}$ (Fig. 6A). As expected from the very low level of adenylyl cyclase, constant low CAMP levels are detected in Ddmyb2-null cells. The results of Figure $6 \mathrm{~B}$ reveal that ectopic expression of ACA in Ddmyb2-null cells is sufficient to induce CAMP oscillations, although the pulses are not as well
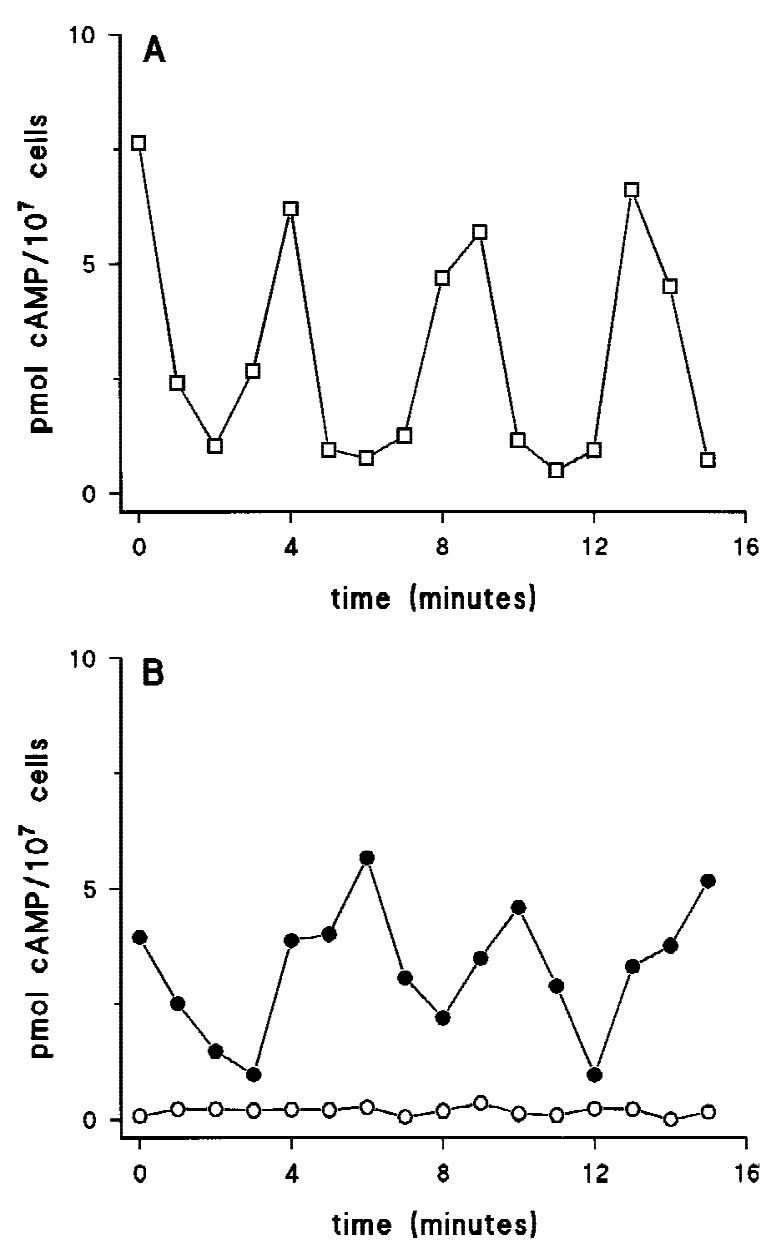

Figure 6. Restoration of CAMP oscillations in Ddmyb2-null cells by ectopic expression of ACA. Cells were starved for $5 \mathrm{hr}$, washed, and resuspended to a density of $10^{8} \mathrm{cell} / \mathrm{ml}$. Samples of the cell suspension were taken at 1-min intervals and used to determine the CAMP concentration. (A) Wild-type Ax3; (B) Ddmyb2-null cells $(\bigcirc)$, Ddmyb2-/ACA cells $(\bullet)$. The results shown are from a typical experiment reproduced two times. 
separated as in wild-type cells; this could be caused by a di sturbed bal ance between phosphodi esterase and adenyIyl cyclase (Parent and Devreotes 1996). As we have shown that exogenous CAMP pulses restore development in Ddmyb2-null cells, the reappearance of autonomous oscillations and normal development in Ddmyb2-/ACA cells implies that DdMyb2 regulates starvation-mediated development mainly by induction of adenylyl cyclase activity.

\section{Discussion}

We have cloned a novel myb-related gene, DdMYB2, which encodes a key component regulating early development in Dictyostelium. DdM yb2 contains three Myb repeats, which is a sequence motif with a DNA-binding helix-turn-helix structure (Frampton et al. 1989; N ess 1996). Many M yb-related proteins from various eukaryotes have been shown to bind DNA in a sequence-specific manner and presumably regulate the expression of genes involved in growth control and differentiation (Lipsick 1996). This may suggest that the new Dictyostelium MYB2 gene encode a transcription factor. We have demonstrated that DdMYB2 is essential for starvation-induced transcription of a set of genes involved in early development. Furthermore, the deduced amino acid sequence of $\mathrm{DdM}$ yb2 contains, besides the $\mathrm{M}$ yb domain, a potential nuclear localization signal, IKKKRERKR, and glutamine-, proline, and acidic amino acid-rich regions that are often found in transactivation domains (Latchman 1990).

DdMYB2 was identified by REMI mutagenesis. The integration event in the original W67 mutant occurred upstream of the DdM yb2 ORF. N everthel ess, W67 and a Ddmyb2-null mutant with a disruption of this ORF have essentially the same phenotype, including the absence of the DdMYB2 transcript. A pparently the insertion took place in the promotor, thereby disrupting DdMYB2 expression. Ddmyb2-null cells fail to aggregate. The expression of some early genes such as CAR1 and $\mathrm{G} \alpha 2$, and cellular responses such as CAM P-mediated chemotaxis and CGMP response are slightly but significantly increased by $2 \mathrm{hr}$ of starvation. In contrast to wildtype cells in which these responses continue to increase during longer starvation, Ddmyb2-null cells stop development at this point. This suggests that DdMYB2 plays a key role in early development as has been observed for other myb-related genes in a variety of organisms. FlbD in Aspergillus nidulans regulates conidiophore development (Wieser and Adams 1995), stonewall in Drosophila is required for germ-cell development (Clark and M CKearin 1996), and in Xenopus c-myb plays an important role in early mesodermal pattern formation (A maravadi and King 1994). In addition, many plant myb-related genes are known to control pigment biosynthesis, and some genes such as GL1 in A rabidopsis are involved in the control of cell fate (Martin and Paz-Ares 1997). Developmental regulations by myb-related genes seem to be widely conserved in higher and lower eukaryotes.

How does DdMYB2 regulate early development in
Dictyostelium? The most striking phenotype of the Ddmyb2-null mutant is the undetectably low level of ACA transcript resulting in very low levels of adenylyl cyclase activity and CAMP relay response. Ectopic expression of ACA under control of a constitutive actin promotor in Ddmyb2-null cells rescues differentiation and morphogenesis. This not only suggests that the absence of ACA is the main cause of the aggregatel ess phenotype of the Ddmyb2-null mutant, but also that DdMyb2 has no other essential function in Dictyostelium. This conclusion is supported by the observation that exogenously added cAM P pulses also restore development of Ddmyb2-null cells. A pparently, the lack of CAMP oscillations because of the absence of ACA is the only defect in Ddmyb2-null cells. All other components of the CAM P signal ing pathway, including surface receptors, G proteins, and effector enzymes, are present in sufficient amounts to transmit CAMP signals. Once CAMP oscillations have started, either by exogenous CAMP pulses or by ectopic ACA expression, positive feedback loops enhance the expression of these components including CAR1 and $G \alpha 2$ to enlarge the oscillations. It also explains the good synergy between wildtype and Ddmyb2-null cells: Wild-type cells provide CAMP oscillations to which Ddmyb2-null cells are fully responsive. This synergy is much better than that be tween wild-type and aca-null cells, probably because CAMP pulses do induce moderate levels of ACA expression, which is independent of its regulation by DdM yb2.

Expression of ACA is one of the earliest responses of cells to starvation. Therefore the factor that induces ACA expression might be activated by the starvation signal and directly enhance the transcription of ACA. It is possible that the ACA promotor is the target of the starvation-activated transcription factor DdMyb2. A model for the onset of Dictyostelium development is shown in Figure 7. Starvation induces the activation of DdM yb2 thereby inducing the expression of ACA. This leads to CAM P oscillations that induce the expression of a set of genes required for chemotaxis, cell aggregation, and further development. Deletion of DdMYB2 can be rescued either by ectopic expression of ACA leading to autonomous CAM P oscillations, or by adding exogenous CAMP pulses that mimic these oscillations. Two pertinent questions require further investigation: How is DdM yb2 activated by starvation, and how does activated DdM yb2 induce the expression of ACA? Studies using mutants with altered PKA activity suggest that this protein kinase might be involved in starvation-mediated ACA expression in Dictyostelium. A mutant with a deletion of the catalytic subunit of PKA is unable to express ACA (Mann et al. 1997). Since DdM yb2 contains two potential PKA phosphorylation sites, KRSYS ${ }^{193}$ in the amino-terminal part and KRVLS ${ }^{475}$ in the third helix of $M$ yb repeat $R 1, D d M$ yb2 activity could be regulated by PKA directly. PKA may al so indi rectly regulate $D$ dM yb2 via phosphorylase kinase that may phosphorylate the serine in IKKKRERKRES ${ }^{418}$; the consensus phosphorylation site overlaps with the putative nuclear localization signal (underlined), suggesting another possible 


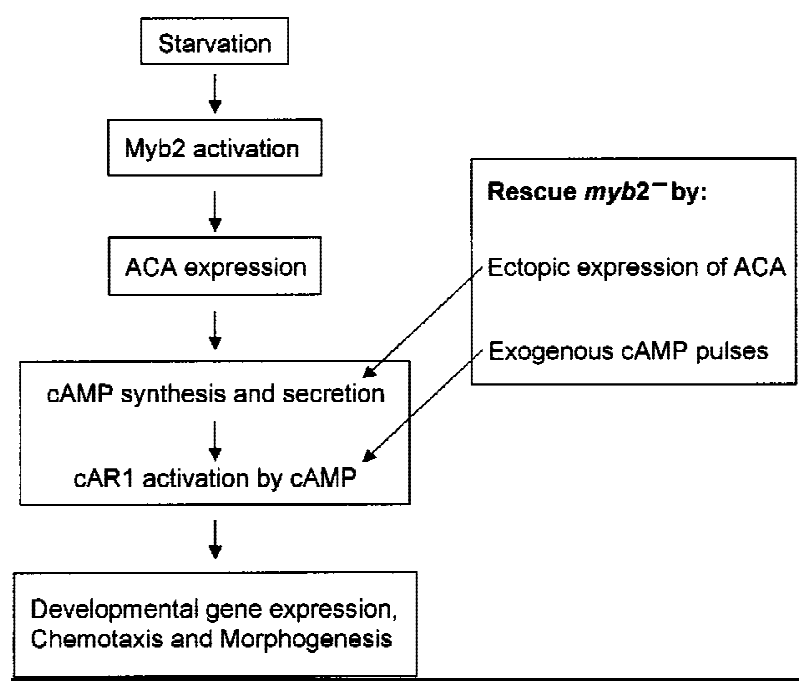

Figure 7. M odel of the regulation of early development in Dictyostelium by Myb2.

mechanism of DdMyb2 regulation at the level of translocation to the nucleus. Sitedirected mutagenesis of DdMyb2 along with PKA mutants might answer how DdM yb2 is activated. Possible interactions with other regulatory proteins should not be ignored, as accumulating evidence suggests that $\mathrm{c}-\mathrm{M} \mathrm{yb}$ and several $\mathrm{Myb}$-related proteins alter gene expression in cooperation with other transcription factors or bridging proteins (Lipsick 1996). In this context it is interesting to note that in DdM yb2, amino acid sequence is less well conserved in the second and third helix of Myb repeats R2 and R3, which are supposed to contact DNA, than in the rest of the Myb domain. This might imply that Myb domains, besides their ability to bind DNA, have other important conserved functions such as protein-protein interactions.

\section{Materials and methods}

Cell culture and development

Dictyostelium discoideum axenic strains $\mathrm{DH} 1$ and $\mathrm{A} \times 3$ were used as wild-type strains. $\mathrm{DH}_{1}$ (ura-) was grown in HG5 medium supplemented with uracil at $100 \mu \mathrm{g} / \mathrm{ml}$, and derived $\mathrm{URA}^{+}$transformants were selected and maintained in FM medium (GIBCO-BRL) lacking uracil. Ax3 was used for transformation using BSR or neo selection markers (Witke et al. 1987; Sutoh 1993); axenic medium was supplemented with $10 \mu \mathrm{g} / \mathrm{ml}$ of blasticidin S or geneticin to select and maintain transformants.

Vegetative cells were obtained from axenic cultures at a cell density of $3 \times 10^{6}$ cells $/ \mathrm{ml}$. For the biochemical assays and $\mathrm{N}$ orthern blotting, cells were starved in $10 \mathrm{~mm}$ phosphate buffer $(\mathrm{pH} 6.5)$ at $10^{7} \mathrm{cells} / \mathrm{ml}$ for the indicated time. When indicated, cells were pulsed with $10^{-7} \mathrm{M}$ CAMP at 5-min intervals.

$M$ orphogenesis was observed on nonnutrient agar plates; cells were plated at low $\left(10^{5} \mathrm{cells} / \mathrm{cm}^{2}\right)$ or high cell density $\left(2 \times 10^{6}\right.$ cells $/ \mathrm{cm}^{2}$ ), from the latter photographs were taken after $30 \mathrm{hr}$ of incubation. For quantification of morphogenesis, cells were put on nonnutrient agar plates at $4 \times 10^{5} \mathrm{cells} / \mathrm{cm}^{2}$ after the indicated length of starvation with or without CAMP pulses; the number of cells not included in fruiting bodies were estimated after $30 \mathrm{hr}$ of incubation.

For synergy experiments, vegetative mutant and wild-type cells were mixed at ratios of $1: 1$ and 9:1. Small droplets $(0.1 \mu \mathrm{l})$ of the mixtures were deposited on a hydrophobic agar plate. The resulting cell density was $\sim 10^{5}$ cells $/ \mathrm{cm}^{2}$. The presence of fruiting bodies was examined after $40 \mathrm{hr}$ of incubation.

\section{REMI mutagenesis}

REMI was carried out as described by Kuspa and Loomis (1992) with the following modification. The plasmid pJB1, which carries the pyr5-6 (URA ${ }^{+}$) gene in Bluescript, was digested with $\mathrm{BamHI}$ and introduced into $\mathrm{DH} 1$ cells along with restriction enzyme D pnll by electroporation. Transformants were selected in FM medium lacking uracil and plated clonally onto LP agar plates in association with E. coli B/r. Aggregateless mutants were picked and characterized by biochemical assays.

pRW67 was recovered from W67 cells as follows: $20 \mu \mathrm{g}$ of genomic DNA isolated from W67 was digested with BgllI. The digested DNA was purified by phenol/chloroform extraction and ethanol precipitation. To promote recircularization, the DN A was ligated at a concentration of $50 \mu \mathrm{g} / \mathrm{ml}$. After ethanol precipitation $0.2 \mu \mathrm{g}$ of the ligated product was used for transformation of SURE electroporation-competent E. coli cells (Stratagene). Transformants harboring the rescued plasmid were selected on ampicillin plates.

Regeneration of W67 mutant from the wild-type strain DH1 was performed by homologous recombination using pRW67 redigested with BgllI. The recombinants were selected by Southern analysis from the URA ${ }^{+}$transformants.

\section{Molecular genetics}

The Ddmyb2-null strains were generated by gene targeting. The targeting construct pMKO1 contains a genomic fragment that encompasses the DdMYB2 coding region in which an $E$. coli vector pBluescript SK $(-)$ (Stratagene) and a BSR cassette (Sutoh 1993) are inserted at the Sacl site. pM KO1 is linearized with Nhel and BgllI and introduced into wild-type Ax3 cells. Transformants were selected for blasticidin resistance. Single colonies were isolated on bacterial plates and analyzed by Southern blots. Clone MD255 was identified as the Ddmyb2null strain and used for the experiments in this study.

CAR1 or ACA were expressed in Ddmyb2-null cells by transformation of MD255 with pJK3 and pCP43, respectively (gifts from P. Devreotes, Johns Hopkins University, Baltimore, MD); both plasmids replicate extrachromosomally, contain a neo selection marker, and express the genes of interest under the control of an actin-15 promoter.

\section{Southern and Northern blotting}

Genomic DN A from AX3 and W67 was purified by $\mathrm{CsCl}$ centrifugation after nuclei isolation, phenol / chloroform extraction, and ethanol precipitation (N ellen et al. 1987). To screen for the recombinants generated by gene targeting, genomic DNA from individual clones was prepared similarly but without $\mathrm{CsCl}$ purification. A pproximately $0.1 \mu \mathrm{g}$ of genomic DNA was used for Southern analysis; $0.4 \mu \mathrm{g}$ of genomic DN A from Ax3 was used for wild-type control. DNA was digested with BgllI, separated on a $0.6 \%$ agarose gel, and transferred on $\mathrm{N}$ ytran filter (Schleicher \& Schuell).

Total RN A from Ax3 and Ddmyb2-null cells was prepared as described by $M$ ann and Firtel (1987); $20 \mu \mathrm{g}$ was used for $\mathrm{N}$ orthern analysis. Samples were separated by el ectrophoresis on a $1 \%$ 
agarose gel containing formal dehyde and transferred on $\mathrm{N}$ ytran filter.

Prehybridization of Southern and N orthern blots was carried out at $65^{\circ} \mathrm{C}$ in the prehybidization solution $(5 \times$ SSC, $4 \times$ Denhardt's, $0.04 \mathrm{mg} / \mathrm{ml}$ sperm DN A, 1\% SDS). Hybridization was carried out at $65^{\circ} \mathrm{C}$ in hybridization buffer (7\% SDS, $0.5 \mathrm{~m}$ phosphate buffer at $\mathrm{pH}$ 7.0) containing ${ }^{32} \mathrm{P}$-label ed probe made by the random primer method (High Prime: Boehringer $M$ annheim). After hybridization, filters were washed with $1 \%$ SDS, $0.5 \mathrm{~m}$ phosphate buffer $(\mathrm{pH} 7.0)$ at $65^{\circ} \mathrm{C}$. The filters were imaged and quantified using a Phosphorlmager (M olecular Dynamics).

\section{Isolation of the myb cDNA}

CDNA clone representing the $3^{\prime}$ end of DdMYB2 was isolated from a $\lambda$ gt11 cDN A library made from 5 -hr starved cells (gift from P. Devereotes), using the 1.3-kb Sacl-Bglll fragment of pRW67. The obtained clone starts at nucleotide 1675 (Fig. 2A). The $5^{\prime}$ part of the CDNA (nucleotide -9 to 1283) was amplified from the same library by PCR using primers 1 and primer 2 (primer 1: 5'-AATAATCATATGACTGCTATATTCC-3', primer 2: 5'-TTTGGTGGAGATCTTATACC-3').

\section{Biochemical assays}

CAMP-binding to cell-surface receptors was determined by the ammonium sulfate stabilization assay (Van Haastert and Kien 1983). The incubation mixture ( $1 \mathrm{ml})$ contained $1 \mathrm{~nm}\left[{ }_{3} \mathrm{H}\right]$ cAM P, $1 \mathrm{~mm}$ dithiothreitol (DTT), 85\% saturated ammonium sulfate, $5 \times 10^{6}$ cells and $50 \mu \mathrm{g} \mathrm{BSA}$. After $5 \mathrm{~min}$ of incubation at $0^{\circ} \mathrm{C}$, the cells were pelleted and radioactivity in the pellet was determined.

For determination of the CGMP and CAMP response, cells were starved for the appropriate period and resuspended in phosphate buffer at $10^{8}$ cells $/ \mathrm{ml}$. Cells were stimulated with $0.1 \mu \mathrm{M}$ CAM P for inducing a cGM P response, and with $5 \mu \mathrm{M} 2$ '-deoxyCAMP and $5 \mathrm{mM}$ DTT for the CAMP response. CAMP oscillations were measured without an exogenous stimulus. The reactions were terminated by the addition of an equal volume of $3.5 \%$ perchloric acid. The levels of CGM P or CAMP were determined in the cell lysates by isotope dilution assays (Snaar-Jagalska and Van Haastert 1994).

For assaying adenylyl cyclase activity, starved cells were harvested and resuspended in lysis buffer $(3 \mathrm{mM} \mathrm{M} \mathrm{gCl} 2,10 \mathrm{~mm}$ Tris- $\mathrm{HCl}$ at $\mathrm{pH} 8.0$ ) at $7.5 \times 10^{7}$ cells $/ \mathrm{ml}$. Cell lysates were pre pared by forced filtration of cells through a Nucleopore filter (pore size $3 \mu \mathrm{m}$ ). Twenty microliters of lysate was immediately mixed with $20 \mu$ of lysis buffer containing $20 \mathrm{~mm}$ DTT, $1 \mathrm{~mm}$ ATP, and $10 \mathrm{~mm} \mathrm{MnSO}_{4}$. The reaction was terminated after 0 , 1,2 , and $4 \mathrm{~min}$ by the addition of $20 \mu \mathrm{l}$ of $3.5 \%$ perchloric acid, and CAMP levels were determined.

Chemotaxis toward CAM P and folic acid was measured by the small population assay (Konijn 1970).

\section{Acknowledgments}

We thank P.N. Devereotes for providing plasmids pJB1, pJK3, and pCP43, the $\mathrm{G} \alpha 2$ probe, and the CDN A library; M.H.K. Linskens for hel pful comments on the text; and J.G. Williams and P. Schaap for their contributions to the collection of aggregateless REMI mutants. W67 was isolated in the laboratory of J.G.W.

The publication costs of this article were defrayed in part by payment of page charges. This article must therefore be hereby marked "advertisement" in accordance with 18 USC section 1734 solely to indicate this fact.

\section{References}

Amaravadi, L. and M.W. King. 1994. Characterization and expression of the Xenopus c-M yb homolog. Oncogene 9: 971974.

Clark, K.A. and D.M. McKearin. 1996. The Drosophila stonewall gene encodes a putative transcription factor essential for germ cell development. Development 122: 937-950.

Frampton, J., A. Leutz, T.J. Gibson, and T. Graf. 1989. DNAbinding domain ancestry. Nature 342: 134.

Garcia-Bustos, J., J. Heitman, and M .N . Hall. 1991. N uclear protein localisation. Biochim. Biophys. Acta 1071: 83-101.

Grotewold E., P. Athma, and T. Peterson. 1991. Alternatively spliced products of the maize $P$ gene encode proteins with homology to the DNA-binding domain of myb-like transcription factors. Proc. Natl. Acad. Sci. 88: 4587-4591.

Johnson, .R.L, R.A. Vaughan, M.J. Caterina, P.J.M. Van Haastert, and P.N. Devreotes. 1991. Overexpression of the cAM P receptor 1 in growing Dictyostelium cells. Biochemistry 30: 6982-6986.

Katzen, A.L., T.B. Kornberg, and J.M. Bishop. 1985. Isolation of the proto-oncogene c-myb from D. melanogaster. Cell 41: 449-456.

Kimmel, A.R. and R.A. Firtel. 1983. Sequence organization in Dictyostelium: Unique structure at the 5 '-ends of protein coding genes. Nucleic Acids Res. 11: 541-552.

_- - 1991. CAMP signal transduction pathways regulating development of Dictyostelium discoideum. Curr. Opin. Genet. Dev. 1: 383-390.

Klein, P.S., T.J. Sun, C.L. Saxe III, A.R. Kimmel, R.L. Johnson, and P.N. Devreotes. 1988. A chemoattractant receptor controls development in Dictyostelium discoideum. Science 241: 1467-1472.

Knecht, D.A., S.M. Cohen, W.F. Loomis, and H.F. Lodish. 1986. Developmental regulation of Dictyostelium discoideum actin gene fusions carried on low-copy and high-copy transformation vectors. Mol. Cell. Biol. 6: 3973-3983.

Konijn, T.M. 1970. Microbiological assay of cyclic 3',5'-AMP. Experientia 26: 367-369.

Kumagai, A., S.K.O. Mann, M. Pupillo, G. Pitt, P.N. Devreotes, and R.A. Firtel. 1988. A molecular analysis of $G$ proteins and control of early gene expression by the cell-surface CAMP receptor in Dictyostelium. Cold Spring Harbor Symp. Quant. Biol. 53: 675-685.

Kumagai, A., M. Pupillo, R. Gundersen, R. Miake-Lye, P.N. Devreotes, and R.A. Firtel. 1989. Regulation and function of G alpha protein subunits in Dictyostelium. Cell 57: 265275.

Kuspa, A. and W.F. Loomis. 1992. Tagging devel opmental genes in Dictyostelium by restriction enzyme-mediated integration of plasmid DN A. Proc. Natl. Acad. Sci. 89: 8803-8807.

Latchman, D.S. 1990. Eukaryotic transcription factors. Biochem. J. 270: 281-289.

Lipsick, J.S. 1996. One billion years of M yb. Oncogene 13: 223235.

Loomis, W.F. 1996. Genetic networks that regulate development in Dictyostelium cells. Microbiol. Rev. 60: 135-150.

Louis, J.M., C.L. Saxe III, and A.R. Kimmel. 1993. Two transmembrane signaling mechanisms control expression of the CAMP receptor gene CAR1 during Dictyostelium development. Proc. Natl. Acad. Sci. 90: 5969-5973.

Majello, B., L.C. Kenyon, and R. Dalla-Favera. 1986. Human c-myb protooncogene: Nucleotide sequence of cDNA and organization of the genomic locus. Proc. Natl. Acad. Sci. 83: 9636-9640.

Mann, S.K.O., and Firtel, R.A. 1987. Cyclic AMP regulation of 
early gene expression in Dictyostelium discoideum: M ediation via the cell surface cyclic AM P receptor. Mol. Cell. Biol. 7: 458-469.

Mann, S.K.O., J.M. Brown, C. Briscoe, C. Parent, G. Pitt, P.N . Devreotes, and R.A. Firtel. 1997. Role of CAM P-dependent protein kinase in controlling aggregation and postaggregative devel opment in Dictyostelium. Dev. Biol. 183: 208-221.

Martin, C. and J. Paz-Ares. 1997. MYB transcription factors in plants. Trends Genet. 13: 67-73.

Nellen, W., S. Datta, C. Reymond, A. Sivertsen, S. Mann, T. Crowley, and R.A. Firtel. 1987. Molecular biology in Dictyostelium: Tools and applications. Methods Cell Biol. 28: 67100.

N ess, S.A. 1996. The Myb oncoprotein: Regulating a regulator. Biochim. Biophys. Acta 1288: F123-F139.

Ogata, K., S. M orikawa, H. N akamura, A. Sekikawa, T. Inoue, H. Kanai, A. Sarai, S. Ishii, and Y. N ishimura. 1994. Solution structure of a specific DN A complex of the Myb DN A-binding domain with cooperative recognition helices. Cell 79: 639-648.

Ohi, R., D. M CCollum, B. Hirani, G.J. Den Haese, X. Zhang, J.D. Burke, K. Turner, and K.L. Gould. 1994. The Schizosaccharomyces pombe $c d c 5^{+}$gene encodes an essential protein with homology to c-M yb. EMBO J 13: 471-483.

Parent, C.A. and P.N. Devreotes. 1996. Molecular genetics of signal transduction in Dictyostelium. Annu. Rev. Biochem. 65: 411-440.

Pitt, G.S., N. Milona, J. Borleis, K.C. Lin, R.R. Reed, and P.N . Devreotes. 1992. Structurally distinct and stage-specific adenylyl cyclase genes play different roles in Dictyostelium development. Cell 69: 305-315.

Rost, B., C. Sander, and R. Schneider. 1994. PHD-an automatic mail server for protein secondary structure prediction. Comput. Appl. Biosci. 10: 53-60.

Shen-Ong, G.L.C. 1990. The myb oncogene. Biochim. Biophys. Acta 1032: 39-52.

Snaar-Jagalska, B.E. and P.J.M. Van Haastert. 1994. G-protein assays in Dictyostelium. Methods Enzymol. 237: 387-408.

Stober-Grässer, U., B. Brydolf, X. Bin, F. Grässer, R.A. Firtel, and J.S. Lipsick. 1992. The Myb DNA-binding domain is highly conserved in Dictyostelium discoideum. Oncogene 7: 589596.

Sun, T.J. and P.N . Devreotes. 1991. Gene targeting of the aggregation stage CAMP receptor CAR1 in Dictyostelium. Genes \& Dev. 5: 572-582.

Sutoh, K. 1993. A transformation vector for Dictyostelium discoideum with a new selectable marker bsr. Plasmid 30: 150154.

Theibert, A. and P.N. Devreotes. 1986. Surface receptor-mediated activation of adenylate cyclase in Dictyostel ium. Regulation by guanine nucleotides in wild-type cells and aggregation deficient mutants. J. Biol. Chem. 261: 15121-15125.

Van Haastert, P.J.M. and E. Kien. 1983. Binding of CAMP and adenosine derivatives to Dictyostelium discoideum cells. Relationships of binding, chemotactic, and antagonistic activities. J. Biol. Chem. 258: 9643-9648.

Wieser, J., and T.H. Adams. 1995. flbD encodes a Myb-like DN A-binding protein that coordinates initiation of AspergilIus nidulans conidiophore development. Genes \& Dev. 9: 491-502.

Witke, W., W. Nellen, and A. N oegel. 1987. Homologous recombination in the Dictyostelium al pha-actinin gene leads to an altered mRNA and lack of the protein. EMBO J. 6: 4143-4148. 


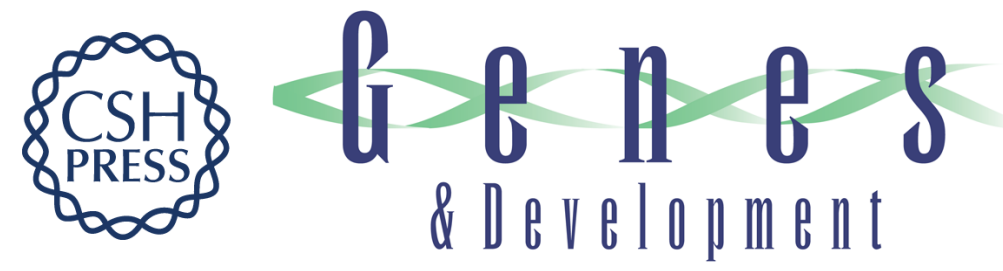

\section{A novel Myb homolog initiates Dictyostelium development by induction of adenylyl cyclase expression}

Hideshi Otsuka and Peter J.M. Van Haastert

Genes Dev. 1998, 12:

Access the most recent version at doi:10.1101/gad.12.11.1738

References This article cites 38 articles, 14 of which can be accessed free at: http://genesdev.cshlp.org/content/12/11/1738.full.html\#ref-list-1

License

Email Alerting

Receive free email alerts when new articles cite this article - sign up in the box at the top Service right corner of the article or click here.

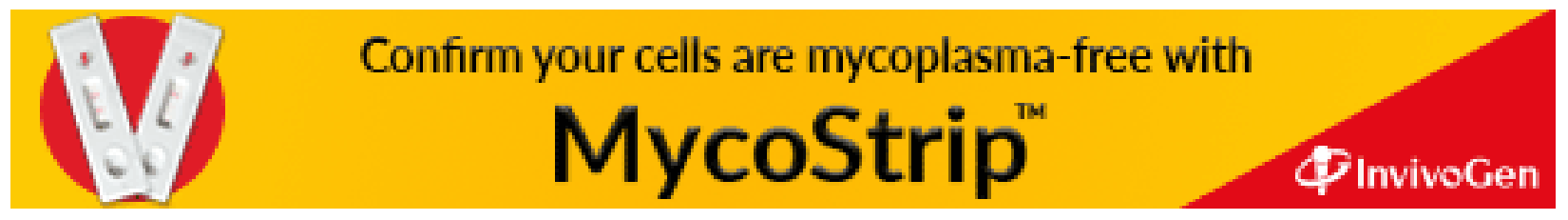

